\title{
ACTIVE PE GAMES - A DETERMINANT IN THE DEVELOPMENT OF RELATIONSHIPS IN THE CHILD DIVERSITY GROUP Veselina Ivanova ${ }^{1}$
}

\begin{abstract}
The article focuses on the active PE game, as a functional dominant in the pre-school age of a child when critical changes in his or her social development occur.

The study was conducted by graduate students in settlements with different demographic characteristics (big city - 2 groups, small town - 2 groups, village - 2 groups) with 120 (3-7-year-old children), from 6 different age groups in kindergartens. Kindergartens and kindergarten groups are randomly chosen.

The experimental work uses diagnostic methods of observation, discussion, sociometric techniques (by J. Moreno), mathematical and statistical methods in its course.

The mobility of the group dynamics, the constancy, the communication and the movement of the participants - children from different game unification; the cohesion of the child group, which represents the level in the development of child relationships are monitored.

It is concluded that active PE games during the period of "game dystrophy", which is distinguished by the specificity of the modern socium, are a determinant, an actual alternative in the development of the children's relationships, which in turn create a perspective in the socialization of the children.
\end{abstract}

UDC Classification: 37.01, DOI: https://doi.org/10.12955/pss.v1.55

Keywords: game unifications, interaction, pedagogical system, social status, dynamics, cohesion of the group

\section{Introduction}

Childhood is a period of formation, characterized by the need for active life. „The activity is shown at the earliest in children's games, in which children reflect the influence of the environment, the activities of the adults, and at the same time transform the reality according to their needs and interests" (Piriov, 1998, p. 129). In and through the game the child creates his ,picture of the world" and of himself (the „Ego-image”). To Gyurova (2006) he is an actor, a subject who concretely and imaginary engages in, shapes and transforms his perceptions of people, nature and the object environment. He enters with the world around him in diverse connections and relationships in the specifics of his age „building in”, of the game motives and game process goals.

In all the variety of games, typical of pre-school age (3-6-7 years), a main place is occupied by active PE games. The reason is rediscovered in their rich motor and emotional content, in the cognitive, educational and healing effect, which they exert on the formative child's personality (Kucher V.O. \& Grygus I.M, 2013; Gwen Dewar, 2019). According to Jean-Jacques Rousseau, these are games with rules and a competitive character which affect the „spiritual, body and emotional life of the child”. Lesgaft stated that ,the active PE game best satisfies the growing organism's need for activity. During the games the mind works briskly and energetically, the mood is joyful... „(Lesgaft, 1877).

Kaburov (1983) defines active PE games as a creative game activity, subject to a particular plot or an idea and aimed at achieving a specific individual or collective goal on the way of overcoming various obstacles. Creativity is a part of the active PE game condition, a part of its rules. One of the reasons for being a preferable activity for modern children is that though played repeatedly, each time the active PE game is played, it varies. This allows children to convert it or even transform it into another (new) game. The playing child is emotionally fascinated by the ability to choose a game role, game combinations, plot, devices, props. „Throughgames new aspects are shown, the unused possibilities of the child's personal potential, socio-moral development, imagination, creativity, cognitive perception and assimilation, activity in all its aspects-cognitive, intellectual, motor, emotionalare revealing" (Doncheva, 2014).

Characteristic of almost all active PE games is that they are collective games. Through the games the child grows accustomed to communicating with peers, age younger or older of the game group. The sense of collectivity and the child's inclusion in the game as a partner brings a rich palette of feelings (Angelova, 2006; Bakermans-Kranenburg et al., 2008; Knafo et al., 2011; Kochanskaet al., 2011).

"In the united children's society game interests are very common and different relationships often arise" (Sette et al., 2017). A game environment is created in which the participants get to know and

\footnotetext{
${ }^{1}$ Veselina Ivanova, Faculty of Education, Trakia University, Stara Zagora, Bulgaria, v_g_chipeva@abv.bg
} 
master group rules, norms of behavior, and share values (Rydell et al., 2005). In the components of the game environment - adaptation, individualization and integration, the socialization process is activated naturally and efficiently (Valkanova, 2006, pp. 20-21; Paulus et al., 2016).

The problem of the child's social development, as a consequence of the modern socium characteristics is in the focus of attention also in other our studies. Their emphasis is on the unfavourable influence of the global processes, IT-society and etc., on the formation of the person, ,growing in a closed, "greenhouse" environment under the continuous supervision of parents, grandmothers, governess" (Ivanova \& Kartselyanska - Stancheva, 2018). These are changes in the modern age, which limit the natural factors for children's socialization - demotivate them for live communication with peers, live games and self-dependence in establishing contacts.

In this context, not surprisingly a child's socialisation is one of the strategic tasks of the pre-school education. In the Republic of Bulgaria, it is objectified through normative documents, in which a basic recommendation is the organization of training, education and socialization to be realized through play and various game forms (Act on pre-school and school education, Regulation №5).

With the child's entry into kindergarten, and his inclusion in a group together with other children, the social situation of his development changes. If so far it has been determined by the relationship „,childadult", the institutionally organized environment adds the relationship "child-child". There is an expanded social space, which is a circumstance for creating a friendly environment for the formation of skills in the child to live in a group.

By the establishment of the new contacts, communication and interaction between children is intensified as well as the process of their social formation. During this process, according to Dimitrova (2017) the active PE game plays a key role. The performance of a game role (a presenter, a captain, etc.) and the game rules in the game group requires consistency of the game actions. The activity of the game interaction is a prerequisite for the achievement of the game goal (performance of the role, observance of the rules, a victory).The game situation itself exists subjectively to the child, puts him in an active position. The joy of the action, as the most characteristic feature of the active PE game, and the satisfaction of the naturally evinced activity, inspires him to transfer it and out of the game. The assessment game situation stimulates the child's assessment approach to his fellow players. The views (criteria) for evaluation are created, altered, enriched and reconsidered in the process of the game contacts between children (Petrova, 2006).

According to Stoyanova (2001) the frequency of the game contacts depends on:

- Often changing game design and gaming content;

- reallocation of the game roles and the change of child's positions in the game situation;

- dynamics in the child's attitudeto the actions, behavior and the role performance of the players; the richness of the real game plan;

- interaction between the game and the real social roles of the playing children.

The exchange of views, which is performed spontaneously on the basis of the game connections and relationships, leads to the creation of game norms. Their awareness and observance on the part of the child influence the social climate between the playing children.

\section{Theoretical formulation of the problem}

In the present the reasons for the need to organize mixed-age groups as an institutional form for the children's care and upbringing are sought in changes happening to the structure and functions of the family, as:

- appearance of non-traditional forms of the family, parallel to the nuclear family;

- growing percentage of the children brought up by one parent;

- accelerated downward trend of the fertility compared to previous years;

- increasing number of families preferring to have one child;

- combination of the woman's career development with the role of a mother and housewife;

- increasingly common gap between reproductive attitudes and reproductive behavior;

- low marriage and high divorce rate, ect. 
In this context, Sabeva (2005) commented that „while in the past the mixed age group was a decision caused by the needs in relation to the defenceless children, it is today not only a social necessity but also a conscious pedagogical concept that has its future."

The inter-age children's society, existing in the conditions of the children's institution as a mixed age group, provides a possibility for child's inclusion in the variety of social contacts forms. „Here the child has a real opportunity to observe, experience and exercise various social behaviors, situations and models available for imitation, and thus to find his social role in the group" (Sabeva, 2005, p.13).

In its essence, the mixed (early age) group is a complex socio-psychological system in which children with different levels of physical, cognitive, social and mental development, and playing culture are communicating. The application of the differentiation in the pedagogues work is not only necessary, but it is a very important principle for the successful realization of all activities in the group - planning and selection of the active PE games for solving the training, educational and health tasks; a combination of methods for the organizationof the activity, training, physical exertion and its regulation; the use of various organizational work forms (morning gymnastics, planned situation, the form active PEgame, etc.); age differences; manners of communication and ect.

For the successful application of the active PE games in a mixed age group the following criteria are met:

- variability and plasticity in the presentation of the game plot, the description of the playing actions, rules, role determination, the presenter, etc.;

- objectiveness and joint applicability of the game variants;

- compliance of the age potentialities - physical, psychomotor and cognitive characteristics of 3-7-year-old children;

- functional influence;

- development of the group solidarity, cooperation, empathy, ect.

The simultaneous group participation in the active PE game has enormous educational potential. Guided by the opinion of specialists that the game has a more developed meaning when it is a child's own practice, Sabeva (2005) found that the mixed age group is a more powerful social factor compared to the single age group. The expanded social space stimulates the deployment of more plots, which means a richer choice of roles and game partners.

An advantage for the child of a mixed group is his ability to observe and participate in a game on a daily basis, directing him to his development perspective. Here the role-playing behaviour of the elder child is a permanent game model, to which the young child strives, led by the motive „To be older" (Sabeva, 2005). According to Flegontova (1990) the elder child should be able to engage the younger child in the game plan, to clarify the game actions from the position of the leading role he occupies.

In the realization of the joint activity throughout the whole period of pre-school age the place of the emotions in the general structure of behaviour is changing. The need for communication expands and deepens in both form and content.

The content of the motivationfor communication with peers (with other children) was studied and revealed experimentally for the age range of 2-7 years. According to Lisina (2001), the subject is prompted to interact by these qualities of the partner, which reveal his Ego, and contribute to selfknowledge. Thereby three sets of motives are formed, which encourage thechildren to communicate with each other:

- business - necessary for the realization of the overall productive activity - game, learning;

- cognitive - related to the qualities of the peers as sources of new information;

- personal - prompting the child to compare (hence self-knowledge) with his equal partner in the activity.

The personal motives for communication, although they form a self-sufficient category, according to Lisina, are necessarily present at both business and cognitive communication. In a real life situation,complex motivation for communication occurs more often. Manifested in the game, it strongly reflects on the relations nature: the individual status of the child, his satisfaction, the degree of awareness of his own position, the mutuality of the sympathies, etc. are changing. 
The present pedagogical study is provoked by the dynamics of the relationships in a diverse age group, whose vivid form is the joint activity with active PE games.

\section{Methodology}

The purpose of the study is to investigate the dynamics of the children's relationships in a mixed group as a consequence of the applied pedagogical system of active PE games in the different regimen moments of the kindergarten.

The study was conducted by graduate students in settlements with different demographic characteristics (big city - 2 groups, small town - 2 groups, village - 2 groups) with 120 (3-7-year-old children), from 6 different age groups in kindergartens. Kindergartens and kindergarten groups are randomly chosen.

\begin{tabular}{|l|l||}
\hline \multicolumn{1}{|c|}{ Table 1: Criteria and indexes for the evaluation of the study results } \\
\hline \multicolumn{1}{|c|}{ Criterial status } & $\begin{array}{l}\text { leaders } \\
\text { favourites } \\
\text { neglected } \\
\text { rejected } \\
\text { motives of preferences }\end{array}$ \\
\hline $\begin{array}{l}\text { Level of initiative in } \\
\text { the game }\end{array}$ & $\begin{array}{l}\text { manifestation of initiative in the game as regards game type, roles, material } \\
\text { environment } \\
\text { ability to maintain the initiative between the peers in the game } \\
\text { indifference }\end{array}$ \\
\hline $\begin{array}{l}\text { Dynamics of the game } \\
\text { unifications }\end{array}$ & $\begin{array}{l}\text { play side by side } \\
\text { games in dyads } \\
\text { groups, bigger than dyads }\end{array}$ \\
\hline Cohesion of the group & $\begin{array}{l}\text { consistency in the actions } \\
\text { activity inthe interactions } \\
\text { acceptance of the group norms } \\
\text { failure to comply with the group norms }\end{array}$ \\
\hline Source: Author & \\
\hline
\end{tabular}

Official approval of a pedagogical system is given, including the specificity of the active PE games as games of collective nature and rules. The open rules are used as a main determinant, regulating the relationships between the players. The applied games invariants are mainly from the group of the active PE games with an organizing character, such as: „Try to find your leader”, „Form up to three”, „Find your flag”, „Watch out for the signal”, „,Birds in nests”,etc.

The effectiveness of the pedagogical technology is reported according to the realization of the following tasks:

- Study of the relationship characteristics between the children in their game activity.

- Research of the changes in the social status of each child.

- Outlining group dynamics and cohesion, defining the level of the children's relationships.

During the experimental work the diagnostic methods observation, talk, sociometric methods "Choice in action” (by J. Moreno) and „Verbal choice” are used for the determination of the social status, numerical and statistical methods.

The mobility of the group dynamics; the constancy, the communication and movement of the participants - children from different game unifications; the cohesion of the child group, which represents the level in the development of child relationships are monitored (Table 1).

\section{Results and Discussion}

\section{Social status analysis}

The social status index of the child in the group is of marginal importance for the obtained rating from the amount of the received choices. The coefficient of the individual status "St" of each child is calculated as a ratio between the number of received choices and the total number of children in the group minus one: 


\section{Number of choices received \\ $\mathrm{St}=\overline{\text { Total number of children in the group }-1}$}

From the analysis of the results during the measurement of the social status by the „Verbal choice" method,four groups were differentiated: leaders, favourites, neglected and rejected. The percentage share-based data on the different categories of children according to their status in the group is averaged for all surveyed persons.

The leaders are $9 \%$, with $\mathrm{St}=0.16$; the favourites $-34 \%$, with approximate $\mathrm{St}=0.5$; the neglected are $24 \%$ with approximateSt $=0.3$ and the rejected $-33 \%$, which is a sign that their $\mathrm{St}=0$.

The demographic characteristics indicate that there is no such social stratification in the village groups. The percentile analysis indicates that the group of rejected is significantly smaller (up to 5$6 \%) \mathrm{St}=0$; the favourites and neglected are equivalent as a quantity of choices (40-45\%) and $\mathrm{St}=$ from 0.4 to 0.6 . Close to these results are the obtained ones in another of our study of the social characteristics of the children's (single-age) group (Ivanova \& Kartselyanska - Stancheva, 2018).

The prevailing part of the studied mixed groups from the villages is of bilingual children (of Roma origin). Although they have difficulties in communicating in Bulgarian, with a few exceptions (mostly 3-4-year-olds), they participate actively in the group's game activity. They show initiative in the choice of an active PE game, variants, and role. They express their willingness to cooperate, observing game norms and coordinating their actions with the other players in the games.

The relationships between the children in the group are determined by the motive of the desired partner choice, answering the question „Why would you prefer to play with this/these children?”. The summarized result shows that the personal (40\% of the investigated) and the assessment (45\%) motives dominate, and the business $(15 \%)$ are indicated as a priority by elder children, entirely falling within the group of leaders and favourites.

Although limited, in mixed groups with contrasting ages there is an interaction on the basis of interest to reach the goal of the group activity (performance of the role, observance of the rules, a victory), implying mutual assistance, goodwill, assistance in the direction a big - small child. In the dominance of the cognitive motives, the small children become for the elder ones curious objects to be studied, whereas in the personal motives predominance in the „big-small child” social model the emotional attitude towards the smaller has the leading role.

The established summarized evaluation motives are with regard to sympathies and possession of moral qualities. With regard to the personal motives, a global assessment of the type - „We are friends!”, "We are relatives", etc. is made. The assessment motives include moral qualities that the chosen one has (kind, honest in the game,...), evaluation of the behaviour, etc.

Results summary analysis of the social status study shows that:

- There are almost no motives, having a social character, which bind the child with the group goals and attitudes in the game activity;

- The social support level is at a low degree. The correlation between the mutual and nonreciprocal choices are rather rare;

- There is no awareness of the personal social status of the children in the group of rejected.

Group cohesion and dynamics analysis

A series of observations, momentary cuts during the game activity are carried out to establish the group cohesion and dynamics. The obtained ,picture" of the results is in correlation with the data from the social status determination.

The characteristics of the relationships in the group are determined by the monitoring of the role and verbal communications. Based on the data from the children's individual manifestations, summarized conclusions are drawn with regard to the group cohesion and dynamics.

The data shows that elder children play in the game activity optionally in dyads, triads and towards the end of the school year in larger game unifications (4-5 children). The children from the group of the rejected play individually, the type of ,side by side". They are predominantly younger, not regularly attending the kindergarten, some of them - coming from dysfunctional families. 
The analysis of the data shows that in the differentiated sub-groups of players there is a consistency of the actions, but there is no steadiness of the game unifications, i.e. they exist for a short period of time (10-15 minutes). Their disintegration is most often provoked by the violation of the group norms. The reason for this is the absence of game habits, especially in younger age children. Some children are also considered striving for imposing their own position in the game unification. Interactions are sought with other sub-groups that are constant in nature, with positive relationships and goodwill. For each mixed group of the studied groups, there are up to two sub-groups with steadiness in the play and permanence in the composition. These are the ones with 3-4 children, which are formed by the leaders and include mostly the favourites, or are differentiated by gender.

The verbal communication is characterized primarily by a verbal expression of an emotional attitude (positive or negative), a demonstration of own opinion, and verbal evaluations to the fellow players. Verbal communication with a social focus, i.e. negotiation, planning of the interactions, defending the position in the group is observed in larger and steadier game unifications, mainly in mixed groups on the principle of similar ages.

The indicated characteristics of the group's verbal communication also affect the quantitative characteristic - more positively presented in the children from kindergartens in small towns.

The analysis of the surveillance data leads to the conclusion that the children's ability to communicate, respectively, the level of the relationships is not at a high level, which affects the group cohesion and from there the social profile of the group(s).

\section{Conclusions}

The social activity of the child, seen in the context of interpersonal relationships in the active PE game, is not unambiguously (only externally) determined. It depends on the internal dynamics, structure and functions of the „I“. Thanks to joint coordination and interactions, the individual "Self“ is born. Reflecting and interiorizing the social relations in the active PE game, the child masters certain norms, social and moral rules, and builds a certain realistic idea of himself. The analysis of the data of the empirical study shows problems related to the children's social development.

Almost half of the groups have an underlined self-centred establishment. The social contacts and interactions of the studied children in the optional activities in the conditions of the kindergarten have a serious deficit. The above mentioned facts are a prerequisite for inadequate socialization. The active PE games are a determinant, an up-to-date alternative, in the development of the child relationships, which in turn create a perspective into the socialization of children.

\section{References}

Angelova, T. (2003). Children active PE games in preparation for school.Stara Zagora: University Publishing houseTrakia University, $23-25$.

Ann-Margret Rydell, Gunilla Bohlin \& Lisa B Thorell (2005). Representations of attachment to parents and shyness as predictors of children's relationships with teachers and peer competence in preschool, Attachment \& Human Development, 7:2, 187-204, DOI: 10.1080/14616730500134282

Dimitrova, Zl. (2017). Active PE games with contemporary plots. Prof.d-r Asen Zlatarov University - Burgas.

Doncheva, Yu. (2014). Consolidating functions of the Bulgarian children folklore games in preschool age (189 games and rosary with their variants), Rousse.

Flegontova, N. P., (1990). Педагогические условия формирования СРИ дошкольников в разновозрастной группе детского сада. http://www.childpsy.ru/dissertations/id/19935.php?sphrase_id=209147.

Gyurova, V. (2009). Pedagogical technologies of game interaction. Sofia, Veda Slovena - ZhG, 127 - 128.

Ivanova, V., Kartselyanska - Stancheva, V. (2018). Modern metamorphoses of relationships in the children's group. Pedagogy, Az-buki National Publishing House for Education and Science, 90, № 2, 184 - 193.

Kaburov, G. (1983). Glossary of physical culture and sport. Sofia: NSA.

Knafo, A., Steinberg, T., \& Goldner, I. (2011). Children's low affective perspective-taking ability is associated with low selfinitiated pro-sociality. Emotion, 11(1), 194-198. https://doi.org/10.1037/a0021240

Kochanska, Gr, A. Sanghag Kim, R. A. Barry, and R. A. Philibert. Children's genotypes interact with maternal responsive care in predicting children's competence: Diathesis-stress or differential susceptibility?

https://www.ncbi.nlm.nih.gov/pmc/articles/PMC3690932/ Dev Psychopathol. Author manuscript; available in PMC 2013 Jun 24.

Kucher V, Grygus I. (2013). The use of outdoor games and their effects on the body of schoolchildren. Pedagogics, psychology, medical-biological problems of physical training and sports.17(1):39-3.

Lesgaft, P. F. (1888). Teaching Physical Education to Schoolchildren Ch. I. P.F. Lesgaft. -St. Petersburg 
Lisina, M. (2001). Communication, personality and psyche of the child. Moscow:Institute of PracticalPsychology. Publishing house of NPO „MODEK” [Lisina, M.I. (2001). Communication, personality and psyche of the child. Moscow: Institute of Practical Psychology; Voronezh: Publishing house of NPO 'MODEK'].

Regulation №5 dated 03.06.2016 for Pre-school education Official-SG issue number 46 from 17.06.2016, in force since 01.08.2016.

Petrova, E.(1986). Integrative functions of the game in the pedagogical process. Sofia: National education.

Piriov, G. (1998). The child. Sofia: Publishing house Veda Slovena -ZhGp.129.

Publishing house of Ministry of Education and Science [Regulation for Pre-school Education (from 17.06.2016, amended and supplemented01.08.2016]. Retrieved, April 28, 2020, from https://www.mon.bg

R Pasco Fearon, Marian J Bakermans-Kranenburg, Marinus H van Ijzendoorn, Anne-Marie Lapsley, Glenn I Roisman (2010). The Significance of Insecure Attachment and Disorganization in the Development of Children's Externalizing Behavior: A Meta-Analytic Study

Sabeva, E. (2005). Socially educative priorities of the mixed-age group. Paisii Hilendarski University Publishing house.

Sette, S., Zava, F., Baumgartner, E. et al. (2017). Shyness, Unsociability, and Socio-Emotional Functioning at Preschool: The Protective Role of Peer Acceptance. Journal of Child and Family Studies, 26(4), 1196-1205. https://doi.org/10.1007/s10826016-0638-8

Stoyanova, D. (2001). Characteristic of communication between children. N: Preschool education, copy.2, 11-15.

Valkanova, V. (2006). Socialization of children in technological environment. Sofia: Saint. Kliment Ohridski University Publishing house.

Zakon za preduchilistnoto I uchilistnoto obrazovanie (2016). [Act on Pre-school and School education]. Retrieved, March 13, 2019, from https://www.lex.bg/bg/laws/ldoc/2136641509 